\title{
Ex vivo laser confocal microscopy findings of cultured Acanthamoeba trophozoites
}

This article was published in the following Dove Press journal:

Clinical Ophthalmology

2I August 2012

Number of times this article has been viewed

\author{
Natsuko Yamazaki' \\ Akira Kobayashi' \\ Hideaki Yokogawa' \\ Yasuhisa Ishibashi ${ }^{2}$ \\ Yosaburo Oikawa ${ }^{3}$ \\ Masaharu Tokoro ${ }^{4}$ \\ Kazuhisa Sugiyama' \\ 'Department of Ophthalmology, \\ Kanazawa University Graduate School \\ of Medical Science, Kanazawa, Japan; \\ ${ }^{2}$ Department of Ophthalmology, East \\ Washinomiya Hospital, Kuki, Japan; \\ ${ }^{3}$ Department of Medical Zoology, \\ Kanazawa Medical University, Kahoku, \\ Japan; ${ }^{4}$ Department of Parasitology, \\ Kanazawa University Graduate School \\ of Medical Science, Kanazawa, Japan
}

Correspondence: Akira Kobayashi |3-I Takara-machi, Kanazawa-shi, Ishikawa-ken 920-864I Japan

$\mathrm{Tel}+8 \mid 762652403$

Email kobaya@kenroku.kanazawa-u.ac.jp
Purpose: The purpose of the current study was to investigate ex vivo laser confocal microscopic findings of cultured Acanthamoeba trophozoites obtained from Acanthamoeba keratitis patients.

Methods: Eight cultured samples of Acanthamoeba trophozoites from eight eyes of seven patients (mean age, 26.9 years; age range, 18-52 years) were used. Seven samples were from corneal scrapings of Acanthamoeba keratitis patients and one sample was from the solution in a soft contact lens case. Ex vivo laser confocal microscopy was performed to qualitatively evaluate the shape and degree of light reflection of the living Acanthamoeba trophozoites.

Results: Ex vivo laser confocal microscopy demonstrated highly reflective, high-contrast Acanthamoeba trophozoites with no walls (mean size, $25.4 \mu \mathrm{m}$; range, 17.1-58.5 $\mu \mathrm{m}$ ). The shapes of the trophozoites were highly pleomorphic, and some showed characteristic acanthopodia by laser confocal microscopy.

Conclusion: Ex vivo laser confocal microscopy was effective in demonstrating cultured Acanthamoeba trophozoites of various shapes and sizes. The observations of the current study may be helpful when similar structures are identified under in vivo conditions.

Keywords: Acanthamoeba, trophozoite, laser confocal microscopy

\section{Introduction}

Acanthamoeba is a ubiquitous, free-living amoeba found in water (eg, swimming pools, hot tubs, tap water, and contact lens solution), air, and soil, but Acanthamoeba keratitis is a relatively new entity. ${ }^{1}$ The first case of Acanthamoeba keratitis was reported in 1974, ${ }^{1}$ and the first case in Japan was reported in $1988 .{ }^{2}$ As the use of soft contact lenses increased in the early 1980s, the incidence of reported Acanthamoeba keratitis increased dramatically. Acanthamoeba keratitis is relatively uncommon, but is a potentially blinding corneal infection. Clinical diagnosis is very difficult, especially in the early phase of the disease, and it is often misdiagnosed and treated as a herpes simplex infection. ${ }^{3}$ A definitive diagnosis is made by confirmation of Acanthamoeba in corneal lesions by direct examination, by corneal biopsy, or by culture. However, these methods are invasive and time-consuming, and are not always routinely available. The invasive methods are often postponed until there is a high index of suspicion for the disease and when there has been no response to treatments for bacterial, viral, and/or fungal keratitis. ${ }^{4}$ Unfortunately, delayed diagnosis of Acanthamoeba keratitis often results in poorer patient outcomes.

In vivo confocal microscopy has been used as a noninvasive technique for the observation of normal and pathological corneal microstructures. The usefulness of 
this device in diagnosis and monitoring the improvement of Acanthamoeba keratitis has been reported. ${ }^{4-11}$ Previously, we $^{12}$ and others ${ }^{13}$ reported ex vivo confocal microscopic images of cultured Acanthamoeba cysts. As a result, Acanthamoeba cysts were observed as highly reflective roundor stellate-shaped high-contrast particles (10-20 microns in diameter). ${ }^{12,13}$ In this study, we investigated ex vivo laser confocal microscopic findings of cultured Acanthamoeba trophozoites.

\section{Patients and methods}

The present study was approved by the Ethical Committee of the Kanazawa University Graduate School of Medical Science and followed the tenets of the Declaration of Helsinki.

\section{Sample collection and culturing of Acanthamoeba trophozoites}

Eight cultured samples of trophozoites from eight eyes of seven patients (mean age, 26.9 years; age range, 18-52 years) were used. Seven samples were from corneal scrapings of Acanthamoeba keratitis patients and one sample was from the solution from a soft contact lens case (Case 3). All patients were seen and treated at the Department of Ophthalmology, Kanazawa University Graduate School of Medical Science between August 2006 and November 2008. The demographic data and treatments are shown in Table 1. The culture medium was an amoeba saline containing $0.012 \% \mathrm{NaCl}$, $0.00035 \% \mathrm{KCl}, 0.0003 \% \mathrm{CaCl}_{2}$, and $0.0004 \% \mathrm{MgCl}_{2} \cdot 7$ $\mathrm{H}_{2} \mathrm{O}$ in $0.05 \mathrm{mM}$ Tris- $\mathrm{HCl}$ with a $\mathrm{pH}$ of 6.8 , supplemented with Escherichia coli. ${ }^{14}$ The detailed culture method was described previously. ${ }^{14}$

\section{Ex vivo laser confocal microscopy}

After applying a large drop of contact gel (Comfort Gel ophthalmic ointment ${ }^{\circledR}$; Bosch and Lomb, GmbH, Berlin, Germany) on the front surface of the microscope lens and ensuring no air bubbles had formed, a Tomo-Cap ${ }^{\circledR}$ (Heidelberg Engineering GmbH, Dossenheim, Germany) was mounted on the holder to cover the microscope lens. A suspension of cultured Acanthamoeba trophozoites was then dropped into a small space created in front of the TomoCap using Scotch ${ }^{\circledR}$ tape. Ex vivo laser confocal microscopy (Heidelberg Retina Tomograph 2-Rostock Cornea Module, HRT 2-RCM; Heidelberg Engineering $\mathrm{GmbH}$ ) was performed to qualitatively evaluate the shape and degree of light reflection of the living Acanthamoeba trophozoites. The HRT 2-RCM uses a 60× water-immersion objective lens (Olympus Europa GmbH, Hamburg, Germany) and utilizes a $670-\mathrm{nm}$ diode laser as the light source, with a $400-\mu \mathrm{m}^{2}$ area of observation.

\section{Results \\ Light microscopic and ex vivo laser confocal microscopic observation}

Light microscopic observation of cultured Acanthamoeba trophozoites showed amorphous Acanthamoeba trophozoites (Figure 1A). In all culture samples, ex vivo laser confocal microscopy demonstrated highly reflective, high-contrast Acanthamoeba trophozoites with no walls (mean size, $25.4 \mu \mathrm{m}$; range, 17.1-58.5 $\mu \mathrm{m}$ ) (Figure 1B-D). The shapes of the trophozoites were highly pleomorphic and some showed characteristic acanthopodia by HRT2-RCM (Figure 1E). In some culture samples, clusters of Acanthamoeba cysts were sporadically observed as highly reflective round- or

Table I Demographic and clinical data for patients with Acanthamoeba keratitis

\begin{tabular}{|c|c|c|c|c|c|c|}
\hline Case & Age (years) & Sex & Eye & Stage & CL & Treatment \\
\hline 1 & 20 & $\mathrm{~F}$ & B & Early & $2 \mathrm{WSCL}$ & $\begin{array}{l}\text { Topical } 0.1 \% \text { micafungin, topical } 0.02 \% \\
\text { chlorhexidine, oral itraconazole }\end{array}$ \\
\hline 2 & 23 & M & $\mathrm{R}$ & Early & $2 \mathrm{WSCL}$ & $\begin{array}{l}\text { Topical } 0.1 \% \text { micafungin, topical } 0.1 \% \\
\text { chlorhexidine, oral itraconazole }\end{array}$ \\
\hline 3 & 18 & M & $\mathrm{L}$ & Early & $2 \mathrm{WSCL}$ & $\begin{array}{l}\text { Topical } 0.1 \% \text { micafungin, topical } 0.1 \% \\
\text { chlorhexidine, oral itraconazole }\end{array}$ \\
\hline 4 & 52 & M & $\mathrm{R}$ & Advanced & $\mathrm{HCL}$ & $\begin{array}{l}\text { Topical } 0.05 \% \text { micafungin, topical } \\
0.05 \% \text { chlorhexidine, oral itraconazole }\end{array}$ \\
\hline 5 & 32 & M & $\mathrm{R}$ & Early & $2 \mathrm{WSCL}$ & $\begin{array}{l}\text { Topical I\% voriconazole, topical } \\
0.02 \% \text { chlorhexidine, oral itraconazole }\end{array}$ \\
\hline 6 & 24 & $\mathrm{~F}$ & $\mathrm{~L}$ & Early & IMSCL & $\begin{array}{l}\text { Topical } 0.05 \% \text { micafungin, topical } \\
0.05 \% \text { chlorhexidine, oral itraconazole }\end{array}$ \\
\hline 7 & 19 & M & $\mathrm{L}$ & Early & $2 \mathrm{WSCL}$ & $\begin{array}{l}\text { Topical } 0.05 \% \text { micafungin, topical } \\
0.05 \% \text { chlorhexidine, oral itraconazole }\end{array}$ \\
\hline
\end{tabular}

Abbreviations: M, male; F, female; R, right eye; L, left eye; B, bilateral eyes; $2 \mathrm{WSCL}$, two-week disposable soft contact lens; IMSCL, one-month disposable soft contact lens; $\mathrm{HCL}$, hard contact lens. 

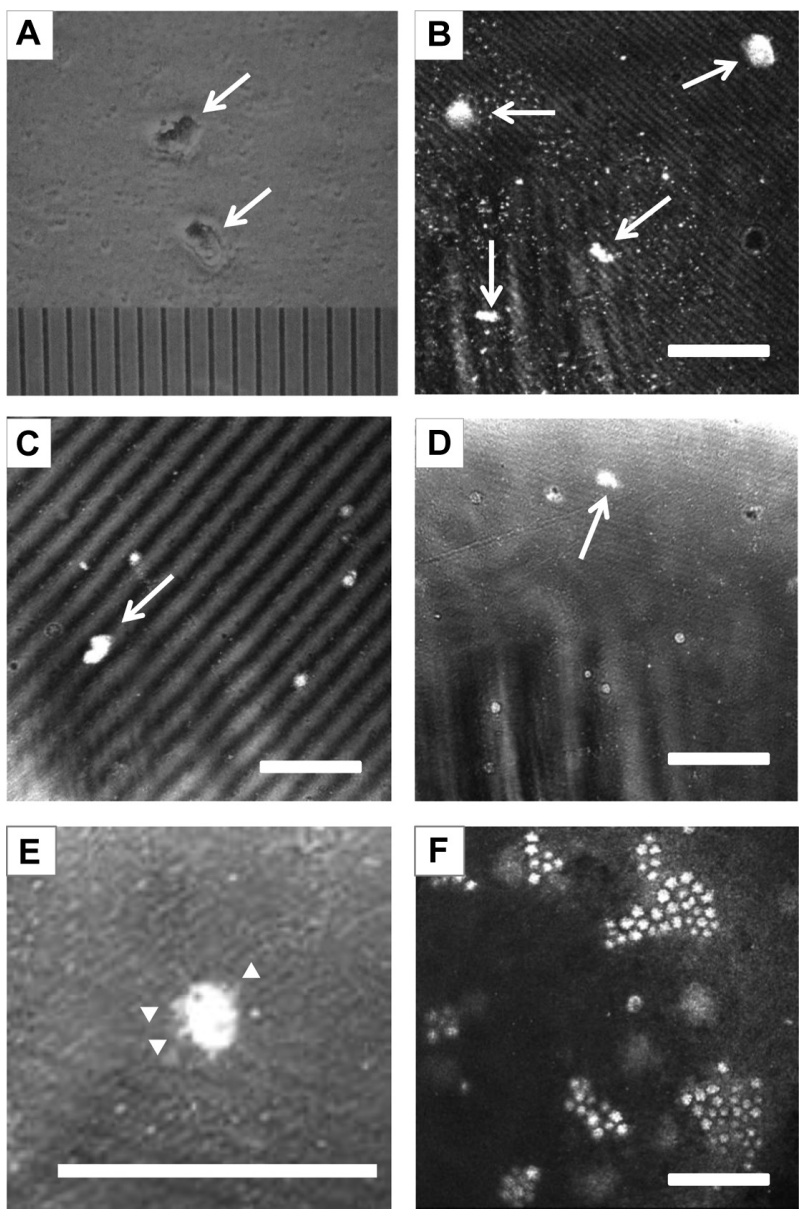

Figure I Light and confocal microscopic observation of cultured Acanthamoeba trophozoites. (A) Light microscopic observation of cultured Acanthamoeba trophozoites (arrows) (one scale $=10 \mu \mathrm{m}$ ). Note that the shape of the Acanthamoeba trophozoites was amorphous. (B) Ex vivo laser confocal microscopic observation of cultured Acanthamoeba trophozoites from Case I. The Acanthamoeba trophozoites were observed as highly reflective, high-contrast amorphous structures. No walls were observed around the trophozoites (bar $=100 \mu \mathrm{m})$. (C) Ex vivo laser confocal microscopic observation of cultured Acanthamoeba trophozoites from Case 2 (bar $=100 \mu \mathrm{m})$. (D) Ex vivo laser confocal microscopic observation of cultured Acanthamoeba trophozoites from Case $6(\mathrm{bar}=100 \mu \mathrm{m})$. (E) Acanthopodia (arrowhead), which are characteristic of Acanthamoeba trophozoites, were observed in some of the trophozoite images (Case 6) (bar $=100 \mu \mathrm{m})$. (F) Clusters of Acanthamoeba cysts were also observed as highly reflective, high-contrast stellateshaped particles 10-20 $\mu \mathrm{m}$ in diameter (Case 2) (bar $=100 \mu \mathrm{m})$.

stellate-shaped particles that were 10-20 $\mu \mathrm{m}$ in diameter (Figure 1F).

\section{Discussion}

In this study, we have reported the ex vivo laser confocal microscopic findings of cultured Acanthamoeba trophozoites obtained from Acanthamoeba keratitis patients. As a result, we consistently observed highly reflective, highcontrast Acanthamoeba trophozoites with no walls (mean size, $25.4 \mu \mathrm{m}$; range, $17.1-58.5 \mu \mathrm{m}$ ). This is consistent with the previously published trophozoite sizes evaluated by in vivo confocal microscopy $\left(25-50 \mu \mathrm{m}\right.$ in diameter). ${ }^{11,13}$ The shapes of the trophozoites were highly pleomorphic not only by light microscopy, but also by confocal microscopy. Acanthamoeba trophozoites were characterized by the presence of acanthopodia, which was also visible by ex vivo laser confocal microscopy.

In clinical settings, direct scraping is still the "gold standard" for definitive diagnosis of Acanthamoeba keratitis. Recently, HRT2-RCM was shown to provide high-resolution images of Acanthamoeba cysts with round or ovoid-shaped structures from $10-20 \mu \mathrm{m}$ in diameter; ${ }^{11-13}$ this allows for the rapid and non-invasive diagnosis of early-stage Acanthamoeba keratitis. However, it was quite difficult to identify Acanthamoeba trophozoites in keratitis patients. Shiraishi et al reported putative Acanthamoeba trophozoites in stromal images obtained by HRT2-RCM in only one case out of nine keratitis patients. ${ }^{13}$ They found that the Acanthamoeba trophozoites showed acanthopodia, nucleus, and karyosomes. ${ }^{13}$ We could not detect definitive Acanthamoeba trophozoites in the corneal epithelium and/or stroma, possibly because they cannot be distinguished from other highly reflective pathological structures. ${ }^{13}$

The limitation of this study is that the size and shape of the Acanthamoeba trophozoites obtained herein may not be readily applicable to images of in vivo conditions in the corneal tissue. However, considering the difficulty of visualizing Acanthamoeba trophozoites in corneal tissue by confocal microscopy, the ex vivo morphological data may be a first step to better recognizing Acanthamoeba trophozoite images in vivo by confocal microscopy.

In conclusion, ex vivo laser confocal microscopy was effective in demonstrating cultured Acanthamoeba trophozoites with various shapes and sizes. The observations of the current study may be helpful when similar structures are identified under in vivo conditions.

\section{Disclosure}

The authors report no conflicts of interest. They received no financial support for this study.

\section{References}

1. Nagington J, Watson PG, Playfair TJ, McGill J, Jones BR, Steele AD Amoebic infection of the eye. Lancet. 1974;2(7896):1537-1540.

2. Ishibashi Y, Matsumoto Y, Watanabe R, et al. A case of Acanthamoeba keratitis: The first case report in Japan. Acta Soc Ophthalmol Jpn. 1988; 92(6):963-972. Japanese.

3. Hammersmith KM. Diagnosis and management of Acanthamoeba keratitis. Curr Opin Ophthalmol. 2006;17(4):327-331.

4. Winchester K, Mathers WD, Sutphin JE, Daley TE. Diagnosis of Acanthamoeba keratitis in vivo with confocal microscopy. Cornea. 1995; 14(1):10-17. 
5. Cavanagh HD, Petroll WM, Alizadeh H, He YG, McCulley JP, Jester JV. Clinical and diagnostic use of in vivo confocal microscopy in patients with corneal disease. Ophthalmology. 1993;100(10):1444-1454.

6. Kaufman SC, Musch DC, Belin MW, et al. Confocal microscopy: a report by the American Academy of Ophthalmology. Ophthalmology. 2004;111(2):396-406.

7. Nakano E, Oliveira M, Portellinha W, de Freitas D, Nakano K. Confocal microscopy in early diagnosis of Acanthamoeba keratitis. J Refract Surg. 2004;20(Suppl 5):S737-S740.

8. Parmar DN, Awwad ST, Petroll WM, Bowman RW, McCulley JP, Cavanagh HD. Tandem scanning confocal corneal microscopy in the diagnosis of suspected Acanthamoeba keratitis. Ophthalmology. 2006; 113(4):538-547.

9. Chew SJ, Beuerman RW, Assouline M, Kaufman HE, Barron BA, Hill JM. Early diagnosis of infectious keratitis with in vivo real time confocal microscopy. CLAO J. 1992;18(3):197-201.
10. Pfister DR, Cameron JD, Krachmer JH, Holland EJ. Confocal microscopy findings of Acanthamoeba keratitis. Am J Ophthalmol. 1996; 121(2):119-128.

11. Matsumoto Y, Dogru M, Sato EA, et al. The application of in vivo confocal scanning laser microscopy in the management of Acanthamoeba keratitis. Mol Vis. 2007;13:1319-1326.

12. Kobayashi A, Ishibashi Y, Oikawa Y, Yokogawa H, Sugiyama K. In vivo and ex vivo laser confocal microscopy findings in patients with early-stage Acanthamoeba keratitis. Cornea. 2008;27(4): 439-445.

13. Shiraishi A, Uno T, Oka N, Hara Y, Yamaguchi M, Ohashi Y. In vivo and in vitro laser confocal microscopy to diagnose Acanthamoeba keratitis. Cornea. 2010;29(8):861-865.

14. Oikawa Y, Kitagawa K, Yagita K, Endo T, Shima I, Ikeda T. Drug susceptibility of Acanthamoeba isolated from 13 Japanese patients with Acanthamoeba keratitis. J Kanazawa Med Univ. 2005;30(2):67-70.
Clinical Ophthalmology

\section{Publish your work in this journal}

Clinical Ophthalmology is an international, peer-reviewed journal covering all subspecialties within ophthalmology. Key topics include: Optometry; Visual science; Pharmacology and drug therapy in eye diseases; Basic Sciences; Primary and Secondary eye care; Patient Safety and Quality of Care Improvements. This journal is indexed on Submit your manuscript here: http://www.dovepress.com/clinical-ophthalmology-journal

\section{Dovepress}

PubMed Central and CAS, and is the official journal of The Society of Clinical Ophthalmology (SCO). The manuscript management system is completely online and includes a very quick and fair peer-review system, which is all easy to use. Visit http://www.dovepress.com/ testimonials.php to read real quotes from published authors. 